\title{
A multisemiotic analysis of 'skinscapes' of female students at three Western Cape universities
}

\author{
Shanleigh Dannica Roux \\ University of the Western Cape
}

\section{INTRODUCTION}

This study examined the role of popular culture on identity expression in female university students. This research specifically focused on the practice of tattooing, which forms a part of popular culture. According to Storey, although popular culture is difficult to define, '[a] $\mathrm{n}$ obvious starting point in any attempt to define popular culture is to say that popular culture is simply culture that is widely favoured or well liked by many people' (2015: 21). Popular culture was used as an analytical tool, which provided valuable insight into the tattooed female body. Tattooing refers to 'the insertion of colored pigment into the dermal layer through a series of punctures of the skin in order to create a permanent marking' (Tiggemann\& Hopkins 2011: 245). This study aimed to advance our understanding of the practice of tattooing among female university students in the Western Cape. Furthermore, this study is located within the sub-discipline of linguistic landscaping, with specific focus on corporeal linguistic landscapes. Linguistic landscapes refer to the " $[\mathrm{t}] \mathrm{he}$ language of public road signs, advertising billboards, street names, place names, commercial shop signs, and public signs on government buildings combines to form the linguistic landscape of a given territory, region, or urban agglomeration' (Landry \& Bourhis 1997: 25). Moving the field of linguistic landscaping forward, is the notion of corporeal landscapes, or skinscapes. According to Peck and Stroud the body is seen as 'a collection of inscriptions in place', with the implication that 'landscapes can be carried on the skin' in the same way that landscapes are carried on public signs (2015).

This study was a departure from many studies in South Africa which still largely look at women in terms of race. By utilizing female students as participants for this research, this study hoped to further problematize the agency of female bodies and the notion of femininity. Tattoos problematize bodies because, as recent studies have shown, work on bodies (i.e. mobility of the body within various 'social worlds' (cf. Kress 2011), focus on the body, skin colour or gender. Tattoos also specifically problematize female bodies because it disrupts the stereotypical perceptions of femininity. The purpose of this study was to advance the understanding of the practice of tattooing among tattooed female university students. The focus of the problem in this study is the semiotics 
of the body, particularly the female body, and the popular cultural practice of tattooing. Furthermore, this study took a new perspective on individuals with tattoos, meaning that instead of merely looking at the 'deviant' side of tattoos, which has been the focus of much academic literature on tattoos; this study looks at the popular cultural side, as practised by female university students.

\section{RESEARGH QUESTIONS AND OBJECTIVES}

\section{Research questions}

This study was motivated by the following research questions:

1. To what extent do beliefs related to gender influence the type of tattoo selected, as well as its size and placement on the body?

2. To what effect does the social context of the participants affect the type of tattoos they have?

3. Are there similarities/differences in the tattoo trends across the different campuses (specifically social structuring of language, if any)?

\section{Objectives}

The study was geared towards:

1. investigating how tattooed female students map their bodies,

2. investigating the kind of semiotic material used in the tattoo designs,

3. exploring the identities depicted by women through their choice of tattoo designs,

4. determining whether placement, design and size of the tattoos are gender-related,

5. determining whether the notion of skinscapes facilitate a deeper understanding of tattooed bodies,
6. establishing whether there is a differential effect in tattoos across campuses and to explore alternative ideas/forms of femininity.

\section{METHODS}

\section{Research Design}

Qualitative as well as quantitative research methods were employed in this study. The primary approach that was employed in this study was qualitative research as the researcher was interested in gaining an understanding of the motivations, values and beliefs (Nachmias\&Nachmias, 1987) which can be interpreted through the tattoos and narratives. Quantitative methodology was used to quantify certain occurrences within the tattoo designs, such as the number of times certain languages were used in the tattoo designs. Quantitative methods were also used to categorize the number of participants that had tattooed specific body parts. This was done as a means of establishing which body parts were popular among the participants.

\section{Setting}

The data was collected at three Western Cape universities: the University of the Western Cape (UWC) in Bellville South, the University of Cape Town (UCT) in Rondebosch, Cape Town, and Stellenbosch University, situated in Stellenbosch.

\section{Duration of study}

The data was collected over a period of four months (November 2014 - February 2015). 


\section{Sample size}

The research population of this study consists of twenty-four female undergraduate students with tattoos at the abovementioned universities. The researcher interviewed eight participants per university.

\section{Sampling technique}

The participants were selected via purposive sampling, meaning that the researcher only interviewed those who met the criteria of the study (cf. Patton 1990, Kumar 1999), that is, female university students with tattoos.

\section{Sample selection}

Participants were inducted in the study based on being female university students at one of the three universities looked at for this study. Undergraduate as well as postgraduate students from different faculties were approached for this study.

\section{Data collection procedure}

The researcher collected data by means of individual interviews, photos, and a new methodology using body silhouettes. At the end of each interview, the participant was given a page with a silhouette of a female body, along with a green, blue and red pen. The participants were asked to use the green pen to indicate where they already have tattoos, the blue pen was used to indicate where they would want to get tattoos and the red pen was used to indicate where they would never get tattoos. The participants were also asked to explain their reasons for marking the particular body parts according to the specific categories. The interviews were recorded with the researcher's voice recorder and the photos were taken with a digital recorder. The researcher captured the tattoos which were visible, such as tattoos on the arms, neck and legs, thus excluding tattoos on private body parts. The pictures, body silhouettes, as well as the notes taken by the researcher, was used for analysis.

\section{Data analysis procedure}

Discourse analysis was used to analyse the interview transcriptions. Quantitative analysis as well as a multimodal analysis were used to analyse the body silhouettes. The pictures of the tattoos were analysed with multimodal/multisemiotic discourse analysis.

\section{FINDINGS}

The narratives as well as the actual tattoos revealed that the females in this study opted for tattoos that are considered to be traditionally feminine. Traditional feminine tattoos refer to tattoos that are small in size, as well as whimsical and inspirational tattoos, which are also characteristics typically associated with women. In addition, popular tattoo placements included the rib cage, back and wrist, while the least popular placements included the calves, private areas and the face. In some cases, it was found that transgressing the norms of traditionally feminine tattoos were seen in a negative light. For example, some participants showed an aversion to big tattoos, as well as tattoos normally associated with males, such as skull and crossbone tattoos, for example. Future research will be able to benefit from this study seeing that it not only shows the usefulness of popular culture as an analytical tool, but it also aims to show that bodies are authored and read, similarly to linguistic landscapes found in public spaces. 


\section{REFERENCES}

Kelly, Kevin. (2006). "From Encounter to Text: Collecting Data in Qualitative Research”. In Martin TerreBlanche, Kevin Durrheim and Desmond Painter (eds.) Research in Practice: Applied Methods for the Social Sciences (pp. 285-319). Cape Town: University of Cape Town Press.

Kress, Gunther. (2011). Multimodality: A Social Semiotic Approach to Contemporary Communication. London: Routledge.

Kumar, Ranjit. (1999). Research Methodology. London: Sage Publications.
Nachmias, David\&Nachmias, Chava. (1987). Research Methods in the Social Sciences. New York: St. Martin's Press.

Patton, Michael. (1990). Qualitative Evaluation and Research Methods. California: Sage.

Storey, John. (2015). Cultural Theory and Popular Culture: An Introduction. New York: Routledge.

Tiggemann, Marika\& Hopkins, Louise. (2011). Tattoos and Piercings: Bodily Expressions of Uniqueness? Body Image, 8, 245-250. 